\title{
Examining the Learnability of English Relative Clauses: Evidence from Kuwaiti EFL Learners
}

\author{
Abdullah M. Alotaibi ${ }^{1}$ \\ ${ }^{1}$ PAAET \& CBE, Kuwait \\ Correspondence: Abdullah Alotaibi, Associate Prof at PAAET \& CBE, P. O. Box 66821 Bayan, Zip Code 43759, \\ Kuwait. Tel: 965-9962-1499. E-mail: alotaibi917@gmail.com
}

Received: September 12, $2015 \quad$ Accepted: January 5, $2016 \quad$ Online Published: January 6, 2016
$\begin{aligned} & \text { doi:10.5539/elt.v9n2p57 } \\ & \text { URL: http://dx.doi.org/10.5539/elt.v9n2p57 }\end{aligned}$

\begin{abstract}
This study aims to test the extent to which 120 Kuwaiti EFL learners are aware of the structure of relative clauses in English through measuring their ability to produce this structure. It also checks whether the English proficiency level of the participants plays a role in their answers on the test. For this purpose, a sentence combination task was used to measure the participants' ability to produce correct relative clauses in English. This test was selected in order to examine the types of error made by the participants pertinent to relative clauses in English. The results reveal that Kuwaiti EFL learners may not be fully aware of the formation rules of relative clauses in English (total mean=60.4\%). The t-test shows that the English proficiency level affected the participants' answers on the test. Specifically, there were statistically significant differences between the answers of the advanced $(76.3 \%)$ and intermediate learners $(44.4 \%)$. The number of errors made by the advanced learners was less than that made by the intermediate learners. Regarding the types of error made by the participants, the most noticeable ones were: deletion of the relative pronoun, wrong relative pronoun, repetitive use of resumptive pronouns, passivisation of the relative clause and problems with the indirect object and genitive relative clauses. The researcher analysed the participants' erroneous answers and provided potential reasons to account for them. Finally, the study concludes with some pedagogical implications and recommendations for further research.
\end{abstract}

Keywords: relative clauses, Second Language Acquisition (SLA), restrictive and non-restrictive relative clauses, Noun Phrase Accessibility Hierarchy (NPAH), Kuwaiti EFL learners

\section{Introduction}

The acquisition of relative clauses has been the subject of numerous debates in the past three decades, mainly due to their complex syntactic behaviour in comparison with other structures. A number of studies have been conducted to get to the bottom of the main sources of difficulty encountering ESL/EFL learners in the process of acquiring relative clauses in English. These studies have given rise to several questions pertaining to the mechanism by which such syntactically-complex structures are acquired by both children and second/foreign language learners (Brown, 1971; Smith, 1974; Keenan \& Hawkins, 1987; Kidd \& Bavin, 2002). Processing English sentences, especially those which contain embedded clauses is particularly difficult to ESL/EFL learners around the globe. Essentially, this difficulty stems from understanding the embedded clause on the one hand, and tracking the main clause on the other (Kuno, 1974). The main function of relative clauses is conveying something about the referent of the head noun. Such function is integral to language communication; hence, mastering the use of these clauses is vitally important to children and ESL/EFL learners alike. This study aims to measure Kuwaiti EFL learners' ability to produce relative clauses in English. It delves deep into the main sources of difficulty that may present themselves throughout the process of acquiring such clauses, and attempts to account for them. For this purpose, the researcher opted for a sentence combination task to investigate whether the participants are able to produce correct relative clauses in English. Ultimately, the study attempts to address some analytic and practical questions that emerge in the course of investigating the acquisition of relative clauses by ESL/EFL learners.

\section{Literature review}

\subsection{Relative Clauses in English}

It has been observed that the relative clause construction has the tendency to appear in all languages, yet not in 
the same form. Thus, it can be thought of as a universal phenomenon. Simply put, a relative clause is a type of subordinate clause that modifies a head noun in the main clause. Its main function is to restrict the possible set of individuals, objects, events, etc. to the subset the speaker intends to talk about. For example, in the sentence: Mary laughed at the boys who hadn't done their homework, Mary did not laugh at all boys; just the ones who hadn't done their homework. Along these lines, English relative clauses can be classified into two types according to the necessity of the information they supply (Lock, 1996). The first type is referred to as a restrictive relative clause since it provides crucial information to clarify the noun phrase (NP) it modifies, whilst a non-restrictive relative clause provides interesting information, yet not necessary (Lock, ibid). The following are two examples that illustrate each type:

(1) a. John who works in the shop downstairs is a very nice man (restrictive)

b. Mary, who works in the shop downstairs, is coming tomorrow to the party (non-restrictive).

A wide variety of relative clauses can be found in English, such variety is commonly categorised on the basis of two main structural features; firstly, the syntactic function of the head, namely, the main clause constituent which is described by the relative clause. Secondly, the syntactic function of the gap, namely, the constituent which is relativized within the relative clause. The gap explains why relative clauses cannot stand on their own; hence, being dependant. Put differently, the relative clause is missing a noun phrase, which is characterised by the gap as in:

(1) The woman [whom [the man saw ]]

\section{Direct Obj}

Even though the head and gap may occupy various syntactic roles in the sentence, studies on the acquisition of relative clauses in the relevant literature focused on four specific types:

(2) a. SS relative clauses which modify the subject of the matrix clause and include a subject gap e.g. the man who lives next door is my brother.

b. OS relative clauses which modify the object of the matrix clause and include a subject gap e.g. I know the man who lives next door.

c. SO relative clauses which modify the subject of the matrix clause and include an object gap e.g. the man whom you know is my brother.

d. OO relative clauses which modify the object of the matrix clause and include an object gap e.g. I know the man who(m) you are talking about.

The fact that the four types discussed above have been the main focus of research on the acquisition of relative clauses can be attributed to what is referred to as the Noun Phrase Accessibility Hierarchy (henceforth NPAH) as outlined by Keenan and Comrie (1977). Specifically, on the basis of approximately fifty languages, the two scholars hypothesised that there is a universal hierarchy that exists in relation to the position which can be relativized in a sentence:

Subj $>$ Direct $\mathrm{Obj}>$ Indirect $\mathrm{Obj}>\mathrm{Obj}$ of adposition $>$ Genitive $>$ Obj of comparison

Simply put, this hierarchy indicates that there exists no language, so far, that can relativize a direct object but cannot do so with a subject. The NPAH also shows that the subject is the highest position on the hierarchy, implying that the syntactic role of the subject is the most accessible one; thus, it can be relativized in virtually all languages around the globe. Examples of these positions are shown below:

(3) a. The woman who saw the ghost

b. The woman whom the boy saw

(Direct Obj)

c. The woman whom the boy gave a locket to

(Indirect Obj)

d. The paper that the woman drew a rabbit on

(Obj of adposition)

e. The woman whose pen the man took

(Genitive)

f. The woman that the man is shorter than

(Obj of comparison)

Another manifestation of the NPAH is the various strategies used in relativisation. Essentially, the gap strategy is the one expected to apply to higher positions on the hierarchy, particularly, the subject position, whereas the resumptive pronoun strategy (copying the pronoun in the relative clause) is the one expected to apply to lower positions on the hierarchy. Thus, having a resumptive pronoun as opposed to a gap in the relativized position makes the lower position much more accessible (Keenan and Cormie, ibid). Therefore, once the resumptive 
pronoun strategy starts working at some point on the hierarchy, then it is expected that all the positions that follow will use a resumptive pronoun strategy rather than a gap (Hawkins, 1999). It has been noticed that the most peculiar aspect about relativisation in English is the fact that it uses a gap strategy in lower positions down the hierarchy e.g. object of adposition rather than a resumptive pronoun strategy. In fact, English does not allow resumptive pronouns normally; thus, if they appeared in some sentences, this means that such sentences are ungrammatical. This peculiarity may cause problems to Arab ESL/EFL learners, especially given the fact that Arabic uses a gap strategy only in subject position. Therefore, these learners will be tempted to use a resumptive pronoun in English, even when it is uncalled for. This observation is thoroughly examined in this study. The next section sheds light on previous studies that tackled the acquisition of English relative clauses.

\subsection{Previous Studies on the Acquisition of Relative Clauses}

According to Hawkins and Chan (1997), relativisation can be a stumbling block to L2 learners. Therefore, there is a pressing need to further investigate this area to attain a better understanding of the acquisition of relative clauses in L2 context. This section reviews some studies conducted on the acquisition of relative clauses in English, focusing on various aspects and hypotheses. For example, using a grammaticality judgment task on eighty-seven participants whose linguistic backgrounds are different e.g. Chinese, Spanish, Persian, etc., Ioup and Kruse (1977) concluded that the acquisition order of relative clauses was as follows: OS> OO $>\mathrm{SO}>\mathrm{SS}$. This conclusion was based on the number of errors which the participants made on the test. Rather than asserting the NPAH, their findings asserted Kuno's (1975) hypothesis which is referred to as the 'Perceptual Difficulty Hypothesis', in which he argues that OS and OO types should be easier than SS and SO since learners tend to avoid embedding. Similarly, Schuman (1980) investigated the ability of 7 international participants who lived in the USA at that time in order to determine the frequency with which various types of relative clauses were used. The results revealed that $\mathrm{OO}$ and OS sentence types were more accessible to the participants rather than SS and SO ones. This also confirms Kuno's (1975) hypothesis which predicts that centre-embedding is the most essential aspect in relative clauses processing.

In order to identify the relationship between transfer and other universal factors in second language acquisition (SLA), Gass (1979) examined the acquisition of relative clauses by adult L2 learners who belonged to different linguistic backgrounds e.g. Korean, Thai, Italian, French, Japanese, Portuguese, Persian, etc. A free composition task and sentence combination task were used to elicit data from 17 high-intermediate and advanced learners. The findings revealed that certain universal phenomena primarily govern the acquisition of English relative clauses by L2 learners. Interestingly, the participants seemed to follow the constraints of the NPAH when they form English relative clauses regardless of the hierarchy found in their own languages, even when the positions do not normally relativize in their native tongues. The NPAH was also manifest in the participants' answers in terms of universal order on the hierarchy. For example, the subject position was the easiest one to relativize being the highest position on the hierarchy, whilst the most problematic one was no other than the object of comparison. The exception was the genitive position. Gass (1979) argued that such position was easy to the participants for two main reasons: (1) the genitive is exclusive to the relative pronoun whose; and (2) its position in the sentence facilitates its relativisation. For instance, in the sentence the woman whose son I adore is wicked, whose son is regarded as one unit; hence, interpreted as the direct object of adore. This explains why the participants were able to provide correct answers on the test.

In his study, Wong (1991) collected 170 English essays written by four ESL learners from five classes in a secondary school in Hong Kong and attempted to check if there was natural order of acquisition of the positions found on the NPAH. By conducting a simple count of the learners' attempts to use a particular type of relative clauses, he argued that such type would be more accessible to the learners as opposed to other types on the hierarchy. After the first count, Wong conducted pre- and post-error-frequency counts of the learners' production of 6 types of relative clauses. The results showed that both analyses were more in line with Kuno's (1975) hypothesis. Therefore, the order of the acquisition of relative clauses by these learners was: $\mathrm{OS}>\mathrm{OO}>\mathrm{SS}>\mathrm{SO}$.

Three hypotheses related to the acquisition of relative clauses were tested by Izumi (2003), namely, the NPAH, Kuno's (1975) hypothesis and SO Hierarchy Hypothesis (SOHH) by Hamiltion (1994) on participants from various linguistic backgrounds. The results indicated that the sequence of difficulty can be predicated based on the positioning of the main clause. Specifically, it is expected that the main object position is easier than the main subject position, and within each main clause positioning, the sequence of difficulty can be predicated based on the types of relative clauses as found on the NPAH. Relying on these results, Izumi (2003) concluded that the two hypotheses NPAH and Kuno's (1975) Perceptual Difficulty Hypothesis complement each other because the former is connected to the influence of canonicity with relative clauses, and the latter is associated with the notion of processing in the main clause. Conversely, the results were not in line with SOHH. 
The literature review reveals that several hypotheses are involved in accounting for the acquisition of relative clauses, the most important of which is the NPAH. Particularly, the majority of studies demonstrated that the acquisition of relative clauses is governed by a developmental trajectory which is in keeping with universal constraints on the formation of relative clauses. However, the literature found on this type of acquisition has been focused mainly on European languages and some Asian languages such as Chinese. Little attention has been given to the acquisition of relative clauses by Arab EFL learners in general and Kuwaiti in particular. Thus, this study aims to bridge this gap. Specifically, it aims to investigate the type of errors made by Kuwaiti EFL learners when they produce relative clauses in English and whether their acquisition is in agreement with any universal factors. The following are the research questions:

1) To what extent are Kuwaiti EFL learners aware of the structure of relative clauses in English?

2) What type of errors, if there, do they make when they produce relative clauses in English and why?

3) Does the English proficiency level of the participants affect their scores on the test?

\section{Methodology}

\subsection{Sample}

The participants consisted of 120 Kuwaiti EFL students at the Public Authority of Applied Education and Training (PAAET) and College of Basic Education (CBE). Their mean age was 23 years old. To validate the results, the participants were chosen based on simple random sampling out of approximately 1000 students. They were divided into two groups according to their scores on the English Placement Test (EPT): those who scored 50-69 on the EPT were considered Intermediate Learners (ILs), whilst those who scored 70 -85 were considered Advanced Learners (ALs). The 120 participants were divided equally into 60 ILs and 60 ALs. Due to the syntactic complexity of relative clauses, the researcher selected only intermediate and advanced learners to take part in this study. Research has also shown that relative clauses are acquired late in L2 context. It is worth noting that the participants have studied English at schools in Kuwait for twelve years and completed two main English courses at the CBE i.e. E 161 and E 261. These courses delineate many complex syntactic structures in English. Also, their participation in the test was voluntary; they were informed that they can leave anytime if they feel stressed or uncomfortable.

\subsection{Instrument}

In order to measure the participants' ability to produce relative clauses in English, a sentence combination task was used as an elicitation instrument (see Appendix A). This task has been used to elicit relative clauses in previous studies (e.g. Gass, 1979; Izumi, 2003; Hamilton, 1994). In the current study, the task included twelve sentences representing the six types of relative clauses as delineated on the NPAH (see example 3) so that every type is represented in two sentences. Additionally, the four types of relative clauses (see example 2) were also included in every clause in order to test the positioning of the head in the main clause. For instance, in the subject relative, one of the sentences is designed as OS and the other as SS to test which of these two types would be more difficult to the participants. The participants were asked to combine the two sentences 1 (the main clauses) and 2 (the relative clause) using a relative pronoun e.g. who, which whose, etc. For instance, sentence 1 (the main clause) Jennifer married John should be combined with sentence 2 (the relative clause) my father gave John the ring in order to produce the IO relative: Jennifer married John whom my father gave the ring to.

\subsection{Statistical Analysis}

In order to examine whether Kuwaiti EFL learners are aware of the correct use of relative clauses in English, an SPSS analysis was used, including the calculations of percentages, means and standard deviations of the participants' answers on the test. These calculations were presented according to the types of relative clauses discussed in section (2.1). A t-test was conducted to check whether the difference between ALs and ILs is statistically significant or not.

\section{Results and Discussion}

The main aim of this study is to measure the ability of Kuwaiti EFL learners to produce correct relative clauses in English, and to account for the errors if found. In order to test whether the participants' English proficiency level affected their answers, a t-test was used. Table 1 below shows the results. 
Table 1. Results of t-test of differences between (ALs) and (ILs)

\begin{tabular}{lllllll}
\hline Proficiency Level & $\mathrm{N}$ & $\mathrm{M}$ & $\mathrm{SD}$ & $\mathrm{t}$ & $\mathrm{df}$ & Sig. \\
\hline Advanced Learners (ALs) & 60 & 7.63 & 3.50 & 1.66 & 118 & $0.034^{* *}$ \\
Intermediate Learners (ILs) & 60 & 4.44 & 2.70 & & & \\
\hline
\end{tabular}

**Significance level $<0.05$.

An examination of Table 1 shows that the difference between the answers of ALs and ILs is lower than (0.05), which means that the difference between the two groups was statistically significant. ALs $(m=7.63)$ performed better than ILs $(\mathrm{m}=4.44)$ on the test. ALs got 550 correct answers out of the overall 720 answers, whereas ILs obtained 320 correct answers out of the overall 720 answers. The number of errors made by ILs (400) exceeded that of ALs (170); hence, the statistical significance. The percentage of correct answers obtained by ALs demonstrates that the English proficiency level of the participants contributed to their correct answers on the test as shown in Table 2.

Table 2. Percentage of correct answers by ALs and ILs on the test

\begin{tabular}{ll}
\hline Proficiency level & Percentage of correct answers \\
\hline Advanced Learners (ALs) & $76.3 \%$ \\
Intermediate Learners (ILs) & $44.4 \%$ \\
Total mean & $60.4 \%$ \\
\hline
\end{tabular}

Table 2 shows that the overall percentage of correct answers by both ALs and ILs (60.4\%) means that Kuwaiti EFL learners may not be fully aware of the structure of relative clauses in English. Numerous errors were made by both groups on the test, showing that they possibly have a vague idea about the formation rules of relative clauses. The number of errors made by both groups in terms of the six types of relative clauses on the NPAH is illustrated in Table 3.

Table 3. Number of errors by ALs and ILs in terms of the 6 types on the NPAH

\begin{tabular}{llllllll}
\hline & Subj & Direct Obj & Indirect Obj & Obj of adposition & Genitive & Obj of comp & Total No. of errors \\
\hline ALs & 15 & 28 & 22 & 35 & 18 & 52 & 170 \\
ILs & 52 & 60 & 61 & 71 & 76 & 80 & 400 \\
\hline
\end{tabular}

Table 3 clearly shows that even though ALs outperformed their ILs counterparts on the test, they still made 170 errors on the six types. A look at Table 3 shows that the most difficult type to both ALs and ILs was the object of comparison. ALs provided 52 faulty answers and ILs provided 80 erroneous answers. This result probably confirms that the object of comparison is the least accessible type on the hierarchy; thus, the most difficult to relativize. Another evidence is manifest in the number of errors made on the subject position; both groups made the least number of errors on that position, which also confirms that the subject position is the most accessible one on the hierarchy; hence, the least difficult type to relativize.

With respect to the types of error found in the participants' answers, the results showed an abundance of errors made by both groups, the most noticeable of which is the use of the resumptive pronoun strategy when it is uncalled for. This type of error was found in several positions on the NPAH. Examples from the participants' faulty answers are found below:

(4) *The teacher rewarded the students who Mary helped him

(5) *Jennifer married John whom my father gave the ring to him

(Indirect obj)

(6) *I saw Mark whom James is more intelligent than him

(Obj of comp)

Possibly, these errors were made as a direct result of transfer from Arabic which uses a resumptive pronoun strategy in all positions down the hierarchy except for the subject. Such results mean that the participants may 
not be aware of the universal factors governing the sequence of relative positions on the hierarchy. Another common type of error detected in the participants' answers was the wrong use of the relative pronoun. Examples from the participants' erroneous answers on the test are shown below:

(7) *I saw Mark whose James is more intelligent than

(8) * Mary helped the teacher which rewarded the students

(Obj of comp)

(9) *George whom house was built by the government met Sally

(10) *I came across the teacher which his car was stolen two days ago

(Genitive)

(Genitive)

The above examples (9-10) show that the participants encountered several difficulties with genitive relative clauses. The reason for such difficulty could be ascribed to the fact that genitive relative clauses require embedding inside a noun phrase. Thus, many participants failed to provide correct answers on the test. Even though the relative pronoun whose is exclusive to genitive relative clauses, the participants still made errors on this item (cf. Gass, 1979). Examples (8) and (10) also demonstrate that some of the participants may not be aware of the animate vs. inanimate aspect of NPs. Therefore, they used an incorrect relative pronoun.

Analysis of the participants' answers on the test exhibited some kind of a pattern in which they passivize the relative clause. A sample of the participants' answers is shown below:

(11) *We planned carefully for the holiday which was ruined by the snow

(Obj of adposition)

(12) *I liked the pasta which was found in the supermarket

(direct Obj)

(13) *Jennifer married John who's given the ring by my father

(Indirect obj)

(14) *Mary helped the teacher rewarded the students

(Subj)

(15) * Mary is smarter than Jack passed the exam.

(Obj of comp)

Based on the above examples, one may argue that some participants may not be aware of the process by which a relative clause is formed in English. Possibly, resorting to passivation to combine the two sentences on the test can be thought of as an avoidance strategy where the participants' use a syntactic structure they know instead of taking a risk with something they may get wrong. A study of examples (14-15) demonstrates that some participants omitted the relative pronoun altogether. This may show that they lack a clear picture of how relative clauses in English are formed, and the criteria based on which the relative pronoun is selected.

An examination of the participants' answers demonstrates that some types of relative clauses were also problematic to Kuwaiti EFL learners. These types are the indirect object and genitive relative clauses. Examples from the participants' answers can be seen below:

(16) * Susan read the essay which Phil sent to

(Indirect Obj)

(17) Susan read the essay which Bill sent

(Indirect Obj)

(18) *The couch which Layla slept is comfortable

(Genitive)

Despite the fact that the participants' may have attained a good English proficiency level, they still faced problems with complex syntactic structures in English. The above examples, taken from the participants' answers on the test, may confirm such observation. The problems detected in examples (16-18) e.g. deleting the personal pronoun may have occurred because the indirect object and the genitive may not be distinctively different from each other in both English and Arabic (see Kenaan, 1975). This lack of difference is caused by the fact that both these types surface as prepositional phrases. Such structure entails the knowledge of syntactic operations such as pied piping i.e. this is Mary to whom I gave my purse last night and prepositional stranding i.e. this is Mary whom I gave my purse to last night which the participants may not have been aware of.

With regard to the four types OS, SO, OO, SS, analysis of the participants' answers showed that the easiest type was OS. This may be accounted for by the fact that the participants only needed to substitute the NP with the relative pronoun. Most of the errors on the test were made on $\mathrm{OO}$ relative clauses since they require relative pronoun fronting. The NPAH is also in play in this context since it was predicted that the subject is the most accessible position on the hierarchy compared to the object position. This predicts that OS and SS types could be easier than $\mathrm{OO}$ and SO types. As a result, an abundance of errors was made on those clauses that involve relativisation of the object.

\section{Conclusion and Recommendations}

The main aim of this study was to check whether Kuwaiti EFL learners are aware of the structure of relative clauses in English by measuring their ability to produce such structures. The English proficiency level of the 
participants was an independent variable to check whether it has an effect on the participants' answers on the test. The overall percentage of correct answers of both ALs and ILs (60.4\%) shows that Kuwaiti EFL learners may not be fully aware of the complex structure of relative clauses in English. The English proficiency level of the participants played a role in their answers on the test. There was a statistically significant difference between the answers of ALs and ILs on the test. The number of errors made by ALs was less compared to that of ILs. An analysis of the types of error made demonstrated that the NPAH was a prominent factor in the participants' answers. Specifically, the least number of errors were made on subject relative clauses since the subject is the most accessible position on the hierarchy. Other types of error were also detected, among which are: deletion of the relative pronoun, wrong relative pronoun, repetitive use of resumptive pronouns, passivisation of the relative clause, problems with indirect object and genitive relative clauses caused by lack of knowledge of certain syntactic operations i.e. prepositional stranding and pied piping. The analysis of the participants' answers demonstarted that the easiest type was OS since the participants only needed to substitute the NP with the relative pronoun. However, OO relative clauses were problematic to the participants since they require relative pronoun fronting.

Based on these results, it is recommended that teachers of English as a second/foreign language need to acquaint EFL learners with the NPAH, showing them the various types of relative clauses and the process by which they are formed. Becoming aware of the NPAH encourages EFL learners to test the limits of their own language, checking whether it is similar to or different from that of English and other languages. This may help them avoid using a resumptive pronoun strategy when it is uncalled for. These learners should also be aware of any syntactic operations that may play a role in forming relative clauses in English such as pied piping and prepositional stranding. Further exploration of other complex syntactic structures and their acquisition by EFL learners is needed to shed light on the mechanisms by which such structures are acquired.

\section{References}

Brown, H. D. (1971). Children's comprehension of relativized English sentences. Child Development, 42, 1923-36. http://dx.doi.org/10.2307/1127595

Gass, S. (1979). Language transfer and universal grammatical relations. Language Learning, 29, 327-344. http://dx.doi.org/10.1111/j.1467-1770.1979.tb01073.x

Hamilton, R. L. (1994). Is implicational generalization unidirectional and maximal? Evidence from relativization instruction in a second language. Language Learning, 44, 123-157. http://dx.doi.org/10.1111/j.1467-1770.1994.tb01096.x

Hawkins, J. A. (1999). Processing complexity and fillergap dependencies across grammars. Language, 75 , 244-285. http://dx.doi.org/10.2307/417261

Hawkins, R., \& Chan, C. Y. H. (1997). The partial availability of Universal Grammar in second language acquisition: The 'failed functional features hypothesis.' Second Language Research, 13(3), 187-226. http://dx.doi.org/10.1191/026765897671476153

Izumi, S. (2003). Processing difficulty in comprehension and production of relative clauses by learners of English as a second language. Language Learning, 53(2), 258-323. http://dx.doi.org/10.1111/1467-9922.00218

Keenan, E. L., \& Comrie, B. (1977). Noun phrase accessibility and universal grammar. Linguistic Inquiry, 8(1), 63-99.

Keenan, E. L., \& Hawkins, S. (1987). The psychological validity of the accessibility hierarchy. In E. Keenan (Ed.), Universal Grammar: 15 Essays (pp. 60-85). London: Croom Helm.

Kidd, E., \& Bavin, E. L. (2002). English-speaking children's comprehension of relative clauses: Evidence for general-cognitive and language-specific constraints on development. Journal of Psycholonguistic Research, 31, 599-617. http://dx.doi.org/10.1023/A:1021265021141

Kuno, S. (1974). The position of relative clauses and conjunction. Linguistic Inquiry, 5, 117-36.

Lock, G. (1996). Functional English grammar. Cambridge: Cambridge University Press.

Sadighi, F. (1994). The acquisition of English restrictive relative clauses by Chinese, Japanese, and Korean adult native speakers. IRAL, 32, 141-153. http://dx.doi.org/10.1017/S0272263107070349

Schumann, L. (1980). The acquisition of English relative clauses by second language learners. In R. C. Scarcella, \& S. D. Krashen (Eds.), Research in second language acquisition. Rowley, Mass: Newbury House. 
Smith, M. D. (1974). Relative clause formation between 29-36 months: A preliminary report. Stanford Papers and Reports on Child Language Development, 8, 104-10.

Wong, J. (1991). Learnability of relative clauses: A Hong Kong Case. Working Papers of the Department of English, 3(1), 108-117.

\section{Appendix A}

Sentence combination task

Level:

Directions: Combine sentence 1 with sentence 2, using the relative pronouns such as who, whom, that, which or whose:

(1)

1. Jennifer married John.

(IO)

2. My father gave the ring to John.

(2)

1. The snow ruined our holiday.

(Obj of adposition)

2. We planned carefully for the holiday.

(3)

1. Mary helped the teacher.

(Subj)

2. The teacher rewarded the students.

(4)

1. The couch is comfortable.

(Genitive)

2. Layla slept on the couch.

(5)

1. Sam won the game.

(Subj)

2. Sam ranked number two.

(6)

1. The paintings attracted the attention of the tourists. (Direct Obj)

2. My father bought the paintings.

(7)
A. Jack passed the exam.
(Obj of comparison)
B. Mary is smarter than Jack.

(8)

1. I liked the pasta.

(Direct Obj)

2. I found the pasta in the supermarket. 
(9)

1. I came across my teacher.

(Genitive)

2. The teacher's car was stolen two days ago.

(10)

1. Susan read the essay.

(Indirect obj)

2. Phil sent the essay to Susan.

(11)

1. I saw Mark.

(Obj of comparison)

2. James is more intelligent than Mark.

(12)

A. George met Sally.

(Genitive)

B. George's house was built by the government.

\section{Copyrights}

Copyright for this article is retained by the author(s), with first publication rights granted to the journal.

This is an open-access article distributed under the terms and conditions of the Creative Commons Attribution license (http://creativecommons.org/licenses/by/3.0/). 